\title{
Body mass index, waist circumference and employment: Evidence from older Irish adults
}

\author{
Irene Mosca* \\ The Irish Longitudinal Study on Ageing (TILDA), Lincoln Gate, Trinity College Dublin, Dublin 2, Ireland
}

\section{A R T I C L E I N F O}

\section{Article history:}

Received 22 February 2012

Received in revised form 1 May 2013

Accepted 1 May 2013

Available online 17 May 2013

\section{JEL classification:}

I10

$\mathrm{J} 21$

$\mathrm{J} 23$

\section{Keywords:}

BMI

Waist circumference

Employment

Older

Ireland

\begin{abstract}
A B S T R A C T
Data from the first wave of the Irish Longitudinal Study on Ageing are used to examine the relationship between fatness and obesity and employment status among older Irish adults. Employment status is regressed on one of the following measures of fatness: BMI and waist circumference entered linearly as continuous variables and obesity as a categorical variable defined using both BMI and waist circumference. Controls for demographic and socioeconomic characteristics, socioeconomic characteristics in childhood and physical, mental and behavioural health are also included. The regression results for women indicate that all measures of fatness are negatively associated with the probability of being employed and that the employment elasticity associated with waist circumference is larger than the elasticity associated with BMI. The results for men indicate that employment is not significantly associated with BMI and waist circumference when these are entered linearly in the regression, but it is significantly and negatively associated with obesity defined either using BMI or waist circumference as categorical variables. The results also indicate that the negative association between obesity and employment status is larger among women. For example, the probability of being employed for the obese category defined using BMI is around 8 percentage points lower for women and 5 percentage points lower for men.
\end{abstract}

(c) 2013 Elsevier B.V. All rights reserved.

\section{Introduction}

Obesity is a global health problem, affecting people of all ages. Rates of obesity and overweight have increased sharply in recent decades in many OECD countries and have now reached 'epidemic proportions'. The World Health Organization estimates that there were 1.5 billion overweight adults and at least five hundred million obese adults worldwide in 2008 (WHO, 2012a). The prevalence of obesity has also increased among older working-age adults, who represent the segment of the population with the highest prevalence of obesity (Angleman et al., 2006; Renna and Thakur, 2010; Wan et al., 2007). Obesity is associated with increased mortality rates and with a

\footnotetext{
* Tel.: +353 (0)1 896 4659; fax: +353 (0)1 8962451.

E-mail address: moscai@tcd.ie.
}

number of conditions that impede health, well-being, physical function and quality of life (WHO, 2012a). In older individuals, obesity can also exacerbate the age-related decline in physical function and lead to frailty (Villareal et al., 2005).

Three possible explanations of why obese individuals might suffer from poorer labour market outcomes are identified in the literature. Firstly, obesity is a debilitating health condition that impacts productivity and employment and is a risk factor for a wide number of diseases, including congestive heart failure, stroke, diabetes, hypertension, arthritis, asthma and sleep apnea (Abbott et al., 1994; Pi-Sunyer, 2002; Renna and Thakur, 2010). Secondly, obese individuals may have certain characteristics that are often difficult to measure but that impact their performance in the labour market, such as lower self-esteem, lower reservation wages and/or higher discount rates (Komlos et al., 2004; Offner, 2001). Thirdly, obese 
individuals may experience discrimination from employers, customers and co-workers due to their physical attributes (Baum and Ford, 2004; Becker, 1973; Hamermesh and Biddle, 1994). In line with this third explanation, Rooth (2009) finds evidence of discrimination against obese workers in a field experiment carried out in Sweden. ${ }^{1}$

The association between obesity and labour market outcomes may be even stronger for older adults. McGarry (2004) hypothesizes that employment outcomes for older workers may be more sensitive to obesity as their labour supply is more sensitive to their health status. Obesity may also accelerate exit from the labour market through early retirement (Renna and Thakur, 2010).

Extensive evidence on the association between obesity and labour market outcomes (wages, labour market status and hours worked) of younger working-age adults has been collected in a number of countries including the US (Averett and Korenman, 1996; Burkhauser and Cawley, 2008; Cawley, 2000, 2004; Norton and Han, 2008; Pagan and Davila, 1997; Register and Williams, 1990; Sabia and Rees, 2012), China (Shimokawa, 2008), the UK (Lindeboom et al., 2010; Morris, 2006, 2007), Denmark (Greve, 2008), Finland (Johansson et al., 2009; Sarlio-Lahteenkorva and Lahelma, 1999), Germany (Bozoyan and Wolbring, 2011), Iceland (Asgeirsdottir, 2011), Sweden (Rooth, 2009) and Europe as a whole (Atella et al., 2008; Brunello and D'Hombres, 2007; Garcia and Quintana-Domeque, 2007; Villar and Quintana-Domeque, 2009). The results found in these studies generally indicate poorer labour market outcomes for obese women compared to their non-obese counterparts. For example, the evidence shows that obese women earn lower wages in the US (Averett and Korenman, 1996; Cawley, 2004) and in Denmark (Greve, 2008) and have lower employment rates in England (Morris, 2007) and in Iceland (Asgeirsdottir, 2011). Results for men are less clear-cut.

Only a few studies investigate the association between obesity and labour market outcomes for older adults. Lundborg et al. (2007) find that in Europe obese adults aged 50 and above suffer from lower employment rates and that older obese women earn less than their non-obese counterparts. The authors explain their findings in terms of poorer health status among older obese individuals and, possibly, employer discrimination towards older obese women. Houston et al. (2009) find that being overweight or obese in young adulthood (at age 25) and obese in middle adulthood (at age 45-55) is associated with early retirement (prior to age 65) in the US. Renna and Thakur (2010) use data from the Health and Retirement Study and find a positive association between obesity and early retirement and between obesity and the incidence of disability in the US.

\footnotetext{
${ }^{1}$ Fictitious applications were sent to real job openings. The applications were sent in pairs and pictures of an obese or non-obese person were randomly assigned to similar applications. The call-back rate for the curricula vitae with weight-manipulated pictures were found to be 6 percentage points lower for men and 8 percentage points lower for women.
}

For reasons of data availability, most surveys use body mass index (BMI) - either self-reported or measured by trained interviewers or nurses - to define fatness and obesity. BMI is defined as the ratio of weight in kilograms to height in metres squared. However, BMI does not distinguish individuals by body composition; in other words, it does not distinguish fat from muscle, bone and other lean body mass. As a result, the BMI of muscular individuals might overestimate the degree to which they are overweight or obese (Burkhauser and Cawley, 2008; Kragelund and Omland, 2005). In addition, the percentage of body fat increases with age, but this increase may not be revealed by BMI (WHO, 1995).

Four recent papers advocate the use of alternative measures of fatness that take into account body composition (Bozoyan and Wolbring, 2011; Burkhauser and Cawley, 2008; Johansson et al., 2009; Wada and Tekin, 2010). Candidates include total body fat, percent body fat, fat mass, fat-free mass, waist circumference and waist-tohip ratio. Each of these measures has its unique strengths and weaknesses (Burkhauser and Cawley, 2008). The evidence collected in these studies suggests that "in the absence of measures of body composition, there is a risk that labour market penalties associated with obesity are measured with bias" (Johansson et al., 2009, p. 36). In a different but related study, Burkhauser et al. (2009) find that the rise in the prevalence of obesity in the US is detectable 10-20 years earlier when skinfold thickness, rather than BMI is used as a measure of fatness.

In this paper, we use data from the first wave of the Irish Longitudinal Study on Ageing to examine the relationship between fatness and obesity and employment status among older Irish adults. We make two contributions to the literature: we focus the analysis on older individuals and use waist circumference as a measure of fatness along with BMI.

Waist circumference is a measure of central obesity, which occurs when excess adiposity is centrally distributed (WHO, 2003). It has at least three advantages over BMI. Firstly, it is highly correlated with abdominal visceral fat (Pouliot et al., 1994; Snijder et al., 2002; Stewart et al., 2003; Zamboni et al., 1998), which tends to increase more than subcutaneous or total body fat with ageing (Beaufrere and Morio, 2000; Villareal et al., 2005). Secondly, it is a stronger predictor of morbidity and mortality (Angleman et al., 2006; Burkhauser and Cawley, 2008; Janssen et al., 2004; van Dijk et al., 2012). Thirdly, it is a 'visible' measure of fatness, which might be interpreted by employers, customers or co-workers as an unattractive physical attribute (Johansson et al., 2009).

Given the recent rise in obesity, Ireland is a particularly interesting site in which to explore the associations between obesity and labour market outcomes. In Ireland, the prevalence of obesity has increased from $9.5 \%$ in 2002 to $11.7 \%$ in 2010 for men aged 15 and above and from $8.4 \%$ to $10.4 \%$ for women of the same age (WHO, 2012b). Harrington et al. (2008) report that $19 \%$ of Irish individuals aged 45-64 were obese in 2007 and 44\% were overweight, based on self-reported BMI. These compare to $16 \%$ and $41 \%$, respectively, in 1997.

The remainder of the paper is structured as follows. Section 2 describes the data. Section 3 presents the 
empirical strategy. The results of the empirical model are reported in Section 4. Section 5 concludes and discusses the findings.

\section{Data}

The Irish Longitudinal Study on Ageing (TILDA) is a nationally representative study of people aged 50 and above (and their spouses or partners of any age) residing in Ireland. The analysis of this paper is based on the first wave of data, which was collected between October 2009 and July $2011 .^{2}$

The Irish Geodirectory, a comprehensive and up-todate listing and mapping of all residential addresses in the Republic of Ireland, was used to generate the TILDA sample. Each residential address was first assigned to one of the 3155 geographical clusters identified using the RANSAM system, which is described in detail in Whelan (1979). A sample of 640 clusters was then selected and stratified by socioeconomic group and geographic location to maintain a sample that was representative of the population. Clusters were selected with a probability proportional to the number of individuals aged 50 and above in each cluster. Forty households were selected from each cluster. Each of the selected addresses was visited by an interviewer, who attempted to ascertain the eligibility of the address, to contact a household member and to determine whether any individuals aged 50 and above lived at that address. All individuals aged 50 and above in each selected household, as well as their partners (even if aged less than 50 themselves), were invited to participate in the study (Savva, 2011).

A total of 8504 participants were recruited. Of these, 8175 were aged 50 and above and 329 were younger partners of eligible individuals. Participants first completed a computer-assisted personal interview (CAPI) in their own homes. Each participant was then invited to travel to one of two health centres (based in Dublin and Cork) for a comprehensive health assessment. Participants who were unable or unwilling to attend a health centre were offered a modified and partial assessment in their own home. Health assessments were carried out by qualified and trained research nurses. Of the 8175 participants aged 50 and above, 5897 underwent a health assessment.

Each participant was also asked to complete a selfadministered questionnaire, which was designed to explore areas that were considered particularly sensitive, such as relationship quality, loneliness, stressful life events, anxiety, worry and alcohol intake. A total of 6910 respondents aged 50 and above completed and returned the self-completion questionnaire. The overall response rate to the study was $62 \%$.

We restrict the sample to individuals who at the time of the interview had not reached the state pension age (and

\footnotetext{
2 The second wave of data was collected between April 2012 and February 2013, and at the time of writing (April 2013) it is being checked and collated by the TILDA survey team in Trinity College Dublin. The expectation is that two additional waves will be collected at two year intervals.
}

so were aged between 50 and 64) and had their height, weight and waist circumference measured in a health assessment, whether at home or in one of the centres. ${ }^{3} \mathrm{We}$ exclude individuals who reported never having engaged in any paid work, either as an employee or self-employed. We use the appropriate survey estimation methods and weights that are available in the data to account for the sampling structure. ${ }^{4}$ The final sample used in the analysis below includes 1732 women and 1471 men.

\section{Empirical strategy}

\subsection{The model}

The outcome studied is whether or not the individual is in employment. Since the indicator of employment is a dichotomous variable, a standard probit model of the following form is employed:

$P\left(E_{i}=1\right)=\Phi\left(\alpha+\beta F_{i}+\gamma X_{i}+\delta C_{i}+\varphi H_{i}\right)$

where $E_{i}=1$ if individual $i$ is in paid employment or selfemployment, 0 otherwise (economically inactive or unemployed); $F_{i}$ is the measure of fatness for individual $i$, captured in a number of ways which are discussed below; $X_{i}$ is a vector of the individual's demographic and socioeconomic characteristics; $C_{i}$ is a vector of the individual's socioeconomic characteristics in childhood; $H_{i}$ is a vector of physical, mental and behavioural health measures for individual $i$ and $\Phi$ is the standard normal cumulative distribution. The explanatory variables are added incrementally to the model. First, only the measure(s) of fatness and age are included. The controls for other demographic and current socioeconomic characteristics are then added. Next, the measures of socioeconomic status in childhood are included and finally the health measures are added to the model.

\subsection{Measures of fatness}

Employment status is regressed on one of the following measures of fatness: BMI and waist circumference entered linearly as continuous variables and obesity as a categorical variable defined using both BMI and waist circumference. Following the World Health Organization classification system, which is based principally on the association between BMI and mortality (WHO, 1995), we categorize respondents as: 'underweight' if their BMI is less than 18.5; 'normal' if their BMI is greater than or equal to 18.5 and less than 25 ; 'overweight' if their BMI is greater than or equal to 25 and less than 30; and 'obese' if their BMI is greater than or equal to 30 . Only one man and 12 women were classified as underweight and are therefore excluded from the final sample. Given the absence of clear cut-off points to define categories of central obesity, we group

\footnotetext{
${ }^{3}$ Weight was measured using a SECA electronic floor scales. Height was measured using a SECA 240 wall-mounted measuring rod. Respondents were asked to remove footwear, any heavy outer clothing and any headgear prior to the measurements. Waist circumference was measured with a standard tape measure.

${ }^{4}$ We use svy commands in STATA 12 that make it possible to take into account the strata, sampling units and sample weights.
} 
Table 1

Descriptive statistics.

\begin{tabular}{|c|c|c|c|c|}
\hline & \multicolumn{2}{|c|}{ Women $(N=1732)$} & \multicolumn{2}{|c|}{ Men $(N=1471)$} \\
\hline & Mean & SD & Mean & SD \\
\hline \multicolumn{5}{|l|}{ Dependent variable } \\
\hline Employed $^{\mathrm{a}}$ & 0.508 & 0.500 & 0.652 & 0.476 \\
\hline \multicolumn{5}{|l|}{ Independent variables } \\
\hline \multicolumn{5}{|l|}{ Measures of fatness } \\
\hline Body mass index (BMI) in $\mathrm{kg} / \mathrm{m}^{2}$ & 28.449 & 5.683 & 29.253 & 4.615 \\
\hline Normal weight $(18.5 \leq \mathrm{BMI}<25)^{\mathrm{a}}$ & 0.281 & 0.449 & 0.157 & 0.364 \\
\hline Overweight $(25 \leq \mathrm{BMI}<30)^{\mathrm{a}}$ & 0.410 & 0.492 & 0.463 & 0.499 \\
\hline Obese $(\mathrm{BMI} \geq 30)^{\mathrm{a}}$ & 0.309 & 0.462 & 0.380 & 0.485 \\
\hline Waist circumference in $\mathrm{cm}$ & 89.756 & 13.365 & 101.102 & 12.144 \\
\hline Waist circumference, quintile 1 & 72.920 & 4.296 & 85.060 & 5.105 \\
\hline Waist circumference, quintile 2 & 81.890 & 1.943 & 94.506 & 1.841 \\
\hline Waist circumference, quintile 3 & 88.251 & 1.761 & 100.383 & 1.651 \\
\hline Waist circumference, quintile 4 & 95.025 & 2.367 & 106.281 & 1.931 \\
\hline Waist circumference, quintile 5 & 109.566 & 9.467 & 118.257 & 8.261 \\
\hline \multicolumn{5}{|l|}{ Demographic and socioeconomic characteristics } \\
\hline Age & 56.844 & 4.225 & 56.801 & 4.277 \\
\hline Lives alone $^{\mathrm{a}}$ & 0.135 & 0.342 & 0.131 & 0.337 \\
\hline Lives with spouse only ${ }^{\mathrm{a}}$ & 0.352 & 0.478 & 0.311 & 0.462 \\
\hline Lives with spouse and/or others ${ }^{a}$ & 0.513 & 0.500 & 0.558 & 0.497 \\
\hline Lives in Dublin ${ }^{\mathrm{a}}$ & 0.256 & 0.436 & 0.229 & 0.420 \\
\hline Lives in another town/city ${ }^{\mathrm{a}}$ & 0.268 & 0.443 & 0.275 & 0.446 \\
\hline Lives in a rural area ${ }^{\mathrm{a}}$ & 0.476 & 0.500 & 0.496 & 0.500 \\
\hline Living children & 2.910 & 1.708 & 2.759 & 1.844 \\
\hline No/primary education ${ }^{a}$ & 0.219 & 0.414 & 0.263 & 0.440 \\
\hline Secondary education $^{\mathrm{a}}$ & 0.540 & 0.498 & 0.503 & 0.500 \\
\hline Third/higher education ${ }^{\mathrm{a}}$ & 0.241 & 0.427 & 0.234 & 0.424 \\
\hline Years spent in employment & 25.872 & 11.217 & 37.194 & 6.879 \\
\hline \multicolumn{5}{|l|}{ Socioeconomic characteristics in childhood } \\
\hline Grew up in poor family ${ }^{\mathrm{a}}$ & 0.191 & 0.393 & 0.254 & 0.435 \\
\hline Both parents working ${ }^{\mathrm{a}}$ & 0.303 & 0.460 & 0.313 & 0.464 \\
\hline Both parents no/primary education ${ }^{\mathrm{a}}$ & 0.587 & 0.492 & 0.638 & 0.481 \\
\hline At least one parent secondary/tertiary education ${ }^{a}$ & 0.313 & 0.464 & 0.285 & 0.451 \\
\hline Missing information on parents' education ${ }^{\mathrm{a}}$ & 0.100 & 0.301 & 0.077 & 0.267 \\
\hline \multicolumn{5}{|l|}{ Measures of physical health } \\
\hline Chronic diseases & 1.445 & 1.267 & 1.310 & 1.238 \\
\hline Poor health ${ }^{\mathrm{a}}$ & 0.175 & 0.380 & 0.215 & 0.411 \\
\hline \multicolumn{5}{|l|}{ Measures of mental health } \\
\hline Depression score (CES-D) & 6.732 & 7.829 & 4.999 & 6.863 \\
\hline Life satisfaction ${ }^{\mathrm{b}}$ & 1.928 & 1.151 & 1.941 & 1.178 \\
\hline \multicolumn{5}{|l|}{ Measures of behavioural health } \\
\hline Never smoked ${ }^{\mathrm{a}}$ & 0.466 & 0.499 & 0.393 & 0.489 \\
\hline Used to smoke & 0.324 & 0.468 & 0.411 & 0.492 \\
\hline Currently smokes $^{\mathrm{a}}$ & 0.210 & 0.407 & 0.196 & 0.397 \\
\hline Vigorous exercise $^{a}$ & 0.237 & 0.426 & 0.421 & 0.494 \\
\hline Alcoholic drinks per day & 2.463 & 2.526 & 4.121 & 4.012 \\
\hline Missing information on alcohol intake ${ }^{a}$ & 0.132 & 0.339 & 0.148 & 0.355 \\
\hline
\end{tabular}

${ }^{a}$ Dummy variable.

b Ranging from 1 = strongly agree to 7 = strongly disagree with the statement 'I am satisfied with my life'.

individuals into sex-specific quintiles, based on all TILDA respondents aged 50-64 with a valid waist circumference measurement.

\subsection{Demographic and socioeconomic characteristics}

We include the following demographic and socioeconomic characteristics: age; household composition (lives alone; lives with spouse only; lives with spouse and/or others including children, grandchildren, siblings, etc.); current area of residence (lives in Dublin; lives in town/city other than Dublin; lives in a rural area); number of living children; education (none/primary; intermediary; tertiary or higher) and number of years spent in employment over the individual's lifetime.

\subsection{Socioeconomic characteristics in childhood}

In controlling for socioeconomic characteristics in childhood, we follow Lindeboom et al. (2010, p. 315). The authors argue that including these variables is important because: (i) compared to their non-obese counterparts, obese individuals may come from families with lower economic and human capital and (ii) coming from more 
Table 2

Percentage in employment by gender, age group, and BMI and waist circumference category.

\begin{tabular}{|c|c|c|}
\hline & $\begin{array}{l}\text { Women }(N=1732) \\
\% \text { employed }\end{array}$ & $\begin{array}{l}\text { Men }(N=1471) \\
\% \text { employed }\end{array}$ \\
\hline \multicolumn{3}{|l|}{ Age group: $50-54$} \\
\hline $\mathrm{BMI}<30$ & 65.6 & 80.1 \\
\hline $\mathrm{BMI} \geq 30$ & $54.0^{* *}$ & 74.7 \\
\hline Waist circumference, quintile $1-4$ & 64.8 & 79.5 \\
\hline Waist circumference, quintile 5 & $51.2^{* *}$ & 72.7 \\
\hline \multicolumn{3}{|l|}{ Age group: 55-59 } \\
\hline $\mathrm{BMI}<30$ & 55.6 & 67.3 \\
\hline $\mathrm{BMI} \geq 30$ & $47.6^{*}$ & 60.9 \\
\hline Waist circumference, quintile $1-4$ & 54.9 & 66.3 \\
\hline Waist circumference, quintile 5 & 46.2 & 59.7 \\
\hline \multicolumn{3}{|l|}{ Age group: 60-64 } \\
\hline $\mathrm{BMI}<30$ & 39.2 & 53.9 \\
\hline $\mathrm{BMI} \geq 30$ & $31.3^{*}$ & 47.8 \\
\hline Waist circumference, quintile $1-4$ & 38.8 & 53.7 \\
\hline Waist circumference, quintile 5 & $29.1^{*}$ & $44.4^{*}$ \\
\hline
\end{tabular}

Note: ${ }^{*}$ Difference between $\mathrm{BMI}<30$ and $\mathrm{BMI} \geq 30$ (waist circumference, quintile $1-4$ and waist circumference, quintile 5 ) significant at $10 \%$ level.

${ }^{* *}$ Difference between $\mathrm{BMI}<30$ and $\mathrm{BMI} \geq 30$ (waist circumference, quintile 1-4 and waist circumference, quintile 5) significant at 5\% level.

${ }^{* * *}$ Difference between $\mathrm{BMI}<30$ and BMI $>30$ (waist circumference, quintile $1-4$ and waist circumference, quintile 5 ) significant at $1 \%$ level.

disadvantaged backgrounds may negatively affect labour market outcomes in later life. A number of studies have also found evidence that socioeconomic factors in childhood are important for health and well-being in later life. For example, Tucker-Seeley and Subramanian (2011) find that adult height among older adults is associated with early life socioeconomic circumstances measured by mother's education and childhood financial hardship.

We include a dummy variable for whether the respondent self-reports to have grown up in a poor family. Controls for whether the respondent's parents ever worked outside the home when the respondent was a child and for the highest qualification attained by the respondent's parents are also added.

\subsection{Measures of health}

Previous studies have found that obesity is a risk factor for a wide number of diseases (WHO, 2012a) and that obese individuals suffer from higher rates of depression (Katz et al., 2000; Roberts et al., 2003; Simon et al., 2008). Hence, obese individuals may perform more poorly in the labour market due to poorer physical or mental health. In order to investigate whether the association between fatness and obesity and labour market outcomes among Irish older adults is attenuated or explained by health, we introduce a number of (admittedly, potentially endogenous) measures of physical and mental health. These include: self-reported health (fair/poor versus excellent/ very good/good); number of chronic diseases reported by the respondent ${ }^{5}$; a depression score, based on the Center for Epidemiologic Studies Depression Scale (for more details on this index, see O'Regan et al., 2011, p. 158) and

\footnotetext{
${ }^{5}$ Number of chronic diseases from: (heart attack or heart failure or angina), cataracts, hypertension, high cholesterol, stroke, diabetes, lung disease, asthma, arthritis, osteoporosis, cancer, Parkinson's disease, peptic ulcer and hip fracture.
}

self-reported life-satisfaction (measured on a scale from 1 to 7 where 1 is 'strongly agree' and 7 'strongly disagree' with the statement 'I am satisfied with my life').

It is also important to include measures of behavioural health. There is extensive evidence in the literature that behavioural risk factors including smoking, heavy drinking and lack of physical exercise have negative health consequences and are associated with higher morbidity and mortality (Chyou et al., 1997; Prescott et al., 2002; Wen et al., 2011). We include the following measures of behavioural health: smoking (in three categories: currently smokes; used to smoke; never smoked); exercise (a dummy variable capturing whether the respondent has engaged in vigorous physical exercise for at least $10 \mathrm{~min}$ in the week prior to the interview); and drinking (standard alcoholic drinks per day consumed on the days when the respondent drinks alcohol and a dummy variable capturing whether information on alcohol intake is missing).

\section{Results}

\subsection{Descriptive statistics}

A descriptive overview of the dependent and independent variables is presented in Table 1 . A total of $30.9 \%$ of women and $38.0 \%$ of men have a BMI equal to or exceeding 30. The average waist circumference for women falling in the fifth quintile of the waist circumference distribution is $109.6 \mathrm{~cm}$, compared to $118.3 \mathrm{~cm}$ for men.

BMI and waist circumference are highly correlated. The correlation coefficient is $0.87(p<0.01)$ for women and $0.88(p<0.01)$ for men. The correlation between the two categories 'BMI $\geq 30$ ' and 'waist circumference, quintile 5' is weaker. For these two categories, the correlation coefficient is $0.65(p<0.01)$ for women and 0.61 $(p<0.01)$ for men.

Table 2 displays the employment distribution by fiveyear age group (50-54; 55-59 and 60-64) and category of 
Table 3

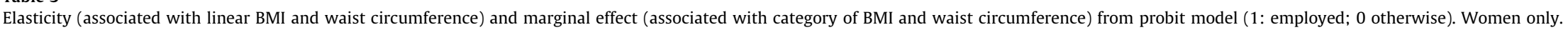
Panel $1 \mathrm{~A}$

\begin{tabular}{|c|c|c|c|c|}
\hline BMI & $\begin{array}{l}\text { (I) } \\
-0.437^{* * *}[3.07]\end{array}$ & $\begin{array}{l}\text { (II) } \\
-0.433^{* * * *}[2.76]\end{array}$ & $\begin{array}{l}\text { (III) } \\
-0.428^{* * * *}[2.72]\end{array}$ & $\begin{array}{l}\text { (IV) } \\
-0.299^{*}[1.82]\end{array}$ \\
\hline \multicolumn{5}{|l|}{ Panel 1B } \\
\hline & (I) & (II) & (III) & (IV) \\
\hline Normal weight $^{\mathrm{a}}$ & R.C. & R.C. & R.C. & R.C. \\
\hline Overweight $^{\mathrm{b}}$ & $0.008[0.24]$ & $0.013[0.48]$ & $0.011[0.39]$ & $0.008[0.28]$ \\
\hline Obese $^{\mathrm{c}}$ & $-0.089^{* * * *}[2.69]$ & $-0.066^{* *}[2.25]$ & $-0.066^{* *}[2.26]$ & $-0.048[1.63]$ \\
\hline
\end{tabular}

\begin{tabular}{|c|c|c|c|c|}
\hline & (I) & (II) & (III) & (IV) \\
\hline Waist circumference & $-0.558^{* * *}[2.98]$ & $-0.550^{* * * *}[2.67]$ & $-0.547^{* * *}[2.64]$ & $-0.359^{*}[1.68]$ \\
\hline
\end{tabular}

Panel 2B

\begin{tabular}{lllll}
\hline & $(\mathrm{I})$ & $(\mathrm{II})$ & $(\mathrm{III})$ & $(\mathrm{IV})$ \\
Quintile 1 & $-0.052[1.30]$ & $-0.026[0.75]$ & $-0.022[0.70]$ & $-0.032[0.90]$ \\
Quintile 2 & $-0.077^{[* *}[1.96]$ & $-0.038[1.07]$ & $-0.035[0.99]$ & $-0.039[1.10]$ \\
Quintile 3 & R.C. & R.C. & R.C. & R.C. \\
Quintile 4 & $-0.092^{* *}[2.29]$ & $-0.051[1.35]$ & $-0.050[1.33]$ & $-0.047[1.26]$ \\
Quintile 5 & $-0.161^{* * *}[4.10]$ & $-0.110^{* * *}[3.06]$ & $-0.106^{* * *}[2.94]$ & $-0.081^{* * *}[2.31]$
\end{tabular}

Panel 1C

\begin{tabular}{|c|c|c|c|c|}
\hline & (I) & (II) & (III) & (IV) \\
\hline $\begin{array}{r}\text { Normal weight } \\
+ \text { overweight }\end{array}$ & R.C. & R.C. & R.C. & R.C. \\
\hline Obese & $-0.094^{* * *}[3.50]$ & $-0.074^{* * *}[3.05]$ & $-0.072^{* * *}[3.00]$ & $-0.052^{* *}[2.21]$ \\
\hline
\end{tabular}

Panel 2C

Obese

\begin{tabular}{lllll}
\hline Quintile 1-4 & (I) & (II) & (III) & (IV) \\
Quintile 5 & R.C. & R.C. & R.C. & R.C. \\
& $-0.104^{* * * *}[3.34]$ & $-0.080^{* * * *}[2.87]$ & $-0.078^{* * * *}[2.78]$ & $-0.051^{*}[1.86]$ \\
& & 1732 & &
\end{tabular}

Note: Abbreviation: R.C. = reference category (I): only age and measure(s) of fatness included.(II): controls for demographic and socioeconomic characteristics added. (III): controls for socioeconomic characteristics in childhood added and (IV): controls for physical, mental and behavioural health added.

a $18.5 \leq \mathrm{BMI}<25$.

b $25 \leq \mathrm{BMI}<30$

c $\mathrm{BMI} \geq 30$.

* Significant at $10 \%$ level.

* Significant at $5 \%$ level.

*** Significant at $1 \%$ level. $z$ statistics in parentheses. 
Table 4

Elasticity (associated with linear BMI and waist circumference) and marginal effect (associated with category of BMI and waist circumference) from probit model (1: employed; 0 otherwise). Men only.

Panel 1A

\begin{tabular}{|c|c|c|c|c|}
\hline & (I) & (II) & (III) & (IV) \\
\hline BMI & $-0.136[1.06]$ & $-0.279^{\circ}[1.90]$ & $-0.250[1.67]$ & $-0.065[0.3 \mathrm{~s}$ \\
\hline \multicolumn{5}{|l|}{ Panel 1B } \\
\hline & (I) & (II) & (III) & (IV) \\
\hline Normal weight $^{\mathrm{a}}$ & R.C. & R.C. & R.C. & R.C. \\
\hline Overweight $^{\mathrm{b}}$ & $0.062^{*}[1.69]$ & $-0.001[0.02]$ & $0.000[0.01]$ & $-0.001[0.04$ \\
\hline Obese $^{c}$ & $-0.007[0.18]$ & -0.052 [1.59] & $-0.046[1.42]$ & $-0.021[0.61$ \\
\hline \multicolumn{5}{|l|}{ Panel 1C } \\
\hline & (I) & (II) & (III) & (IV) \\
\hline $\begin{array}{r}\text { Normal weight } \\
+ \text { overweight }\end{array}$ & R.C. & R.C. & R.C. & R.C. \\
\hline Obese & $-0.053^{* *}[2.04]$ & $-0.051^{* *}[2.23]$ & $-0.046^{* *}[2.01]$ & $-0.019[0.8$ \\
\hline $\mathrm{N}$ & \multicolumn{4}{|c|}{1471} \\
\hline
\end{tabular}

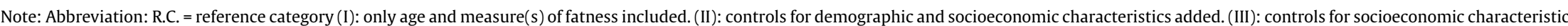
in childhood added (IV): controls for physical, mental and behavioural health added.

$18.5 \leq \mathrm{BMI}<25$

$25 \leq \mathrm{BMI}<30$

BMI $\geq 30$.

* Significant at $10 \%$ level.

** Significant at $5 \%$ level.

${ }^{* * *}$ Significant at $1 \%$ level. $z$ statistics in parentheses.

\begin{tabular}{|c|c|c|c|c|}
\hline Panel 2A & & & & \\
\hline & (I) & (II) & (III) & (IV) \\
\hline Waist circumference & $-0.241[1.41]$ & $-0.358^{*}[1.75]$ & $-0.314[1.52]$ & $-0.021[0.10]$ \\
\hline
\end{tabular}

\section{Panel 2B}

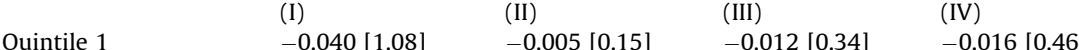

Quintile $2-0.074^{*}[1.90]-0.060^{*}[1.73]-0.062^{*}[1.80]-0.059^{*}[1.71]$

Quintile 3

R.C.

R.C.

$\begin{array}{llll}-0.055[1.42] & -0.075^{* * *}[2.20] & -0.078^{* * *}[2.29] & -0.060^{*}[1.75] \\ -0.110^{* * * *}[2.96] & -0.080^{* * *}[2.52] & -0.008^{* * *}[2.51] & -0.044[1.40]\end{array}$

R.C.

Panel 2C

\begin{tabular}{lllll}
\hline & (I) & (II) & (III) & (IV) \\
Quintile $1-4$ & R.C. & R.C. & R.C. & R.C.
\end{tabular}

Quintile 5

$-0.067^{* * *}[2.26]$

$-0.045^{*}[1.75]$

$-0.042[1.62]$

$-0.009[0.38]$

-0.045
1471


Table 5

Marginal effect [and $z$ statistics] associated with each independent variable from probit model (1: employed; 0 otherwise). Women only $(N=1732)$.

\begin{tabular}{|c|c|c|c|c|}
\hline & $(1)$ & $(2)$ & (3) & (4) \\
\hline \multicolumn{5}{|l|}{ Measures of fatness } \\
\hline BMI & $-0.004^{*}[1.85]$ & - & - & - \\
\hline Obese $(\mathrm{BMI} \geq 30)$ & - & $-0.052^{* *}[2.21]$ & - $\quad$ r & - \\
\hline Waist circumference & - & - & $-0.001^{*}[1.69]$ & - \\
\hline Waist circumference, quintile 5 & - & - & - & $-0.051^{*}[1.86]$ \\
\hline \multicolumn{5}{|l|}{ Demographic and socioeconomic characteristics } \\
\hline Age & $-0.026^{* * *}[9.41]-0.026^{* * *}[9.46]$ & $-0.026^{* * *}[9.31]$ & $-0.026^{* * *}[9.38]$ & \\
\hline Lives with spouse only & $-0.088^{* *}[2.47]$ & $-0.087^{* *}[2.47]$ & $-0.089^{* *}[2.52]$ & $-0.088^{* *}[2.50]$ \\
\hline Lives with spouse and/or others & $-0.076^{* *}[2.10]$ & $-0.075^{* *}[2.06]$ & $-0.077^{* *}[2.13]$ & $-0.079^{* *}[2.17]$ \\
\hline Lives in another town/city & $-0.026[0.92]$ & $-0.025[0.88]$ & $-0.027[0.93]$ & $-0.027[0.96]$ \\
\hline Lives in rural area & $0.013[0.46]$ & $0.014[0.50]$ & $0.012[0.44]$ & $0.011[0.42]$ \\
\hline Living children & $0.022^{* * *}[2.96]$ & $0.022^{* * *}[2.92]$ & $0.022^{* * * *}[2.96]$ & $0.022^{* * * *}[2.96]$ \\
\hline No/primary education & $-0.164^{* * *}[4.30]$ & $-0.163^{* * *}[4.30]$ & $-0.164^{* * *}[4.32]$ & $-0.164^{* * *}[4.33]$ \\
\hline Secondary education & $-0.033[1.35]$ & $-0.034[1.39]$ & $-0.034[1.38]$ & $-0.034[1.39]$ \\
\hline Years spent in employment & $0.016^{* * * *}[18.37]$ & $0.016^{* * * *}[18.36]$ & $0.016^{* * *}[18.30]$ & $0.016^{* * * *}[18.36]$ \\
\hline \multicolumn{5}{|l|}{ Socioeconomic characteristics in childhood } \\
\hline Grew up in a poor family & $-0.019[0.60]$ & $-0.019[0.61]$ & $-0.019[0.61]$ & $-0.018[0.57]$ \\
\hline Both parents working & $-0.017[0.68]$ & $-0.017[0.71]$ & $-0.017[0.69]$ & $-0.017[0.70]$ \\
\hline At least one parent secondary/tertiary education & $-0.036[1.41]$ & $-0.034[1.32]$ & $-0.036[1.42]$ & $-0.034[1.33]$ \\
\hline Missing information on parents' education & $-0.015[0.36]$ & $-0.012[0.30]$ & $-0.014[0.35]$ & $-0.015[0.36]$ \\
\hline \multicolumn{5}{|l|}{ Measures of physical health } \\
\hline Chronic diseases & $-0.026^{* * * *}[2.86]$ & $-0.026^{* * *}[2.89]$ & $-0.026^{* * * *}[2.87]$ & $-0.027^{* * *}[2.98]$ \\
\hline Poor health & $-0.077^{* *}[2.40]$ & $-0.077^{* *}[2.40]$ & $-0.079^{* *}[2.45]$ & $-0.078^{* *}[2.43]$ \\
\hline \multicolumn{5}{|l|}{ Measures of mental health } \\
\hline Depression score (CES-D) & $-0.003^{* *}[2.07]$ & $-0.003^{* *}[2.09]$ & $-0.003^{* *}[2.08]$ & $-0.003^{* *}[2.04]$ \\
\hline Life satisfaction & $-0.018^{*}[1.66]$ & $-0.018^{*}[1.65]$ & $-0.018^{*}[1.69]$ & $-0.018^{*}[1.70]$ \\
\hline \multicolumn{5}{|l|}{ Measures of behavioural health } \\
\hline Used to smoke & $0.001[0.04]$ & $0.001[0.05]$ & $0.002[0.08]$ & $0.004[0.1]$ \\
\hline Currently smokes & $-0.067^{* *}[2.22]$ & $-0.066^{* *}[2.20]$ & $-0.063^{* *}[2.10]$ & $-0.062^{* *}[2.08]$ \\
\hline Vigorous exercise & $0.028[1.06]$ & $0.027[1.03]$ & 0.029 [1.09] & $0.027[1.02]$ \\
\hline Alcoholic drinks per day & $0.000[0.03]$ & $0.000[0.01]$ & $0.000[0.07]$ & $0.000[0.01]$ \\
\hline Missing information on alcohol intake & $-0.028[0.06]$ & $-0.021[0.04]$ & $-0.048[0.10]$ & $-0.018[0.04]$ \\
\hline
\end{tabular}

Note: Reference category for variables with at least three categories: lives alone; lives in Dublin; tertiary or higher education; both parents no/primary education; never smoked.

* Significant at $10 \%$ level.

** Significant at $5 \%$ level.

*** Significant at $1 \%$ level.

BMI and waist circumference, for men and women separately. The table shows that individuals with a BMI equal to or exceeding 30 and in the top quintile of the waist circumference distribution are less likely to be in employment. The differences between the obese and non-obese categories are, however, statistically significant at $5 \%$ only for women aged 50-54.

\subsection{Correlation of fatness and obesity with employment for women}

Results from the probit models for women are reported in Table 3. Panels $1 \mathrm{~A}$ and $2 \mathrm{~A}$ list the elasticities associated with BMI and waist circumference entered linearly as continuous variables. Panels $1 \mathrm{~B}$ and $1 \mathrm{C}$ display the marginal effects associated with obesity as a categorical variable defined using BMI. Panels $2 \mathrm{~B}$ and $2 \mathrm{C}$ list the marginal effects associated with obesity as a categorical variable defined using waist circumference. The first column of each panel (I) shows the results of the model that includes only age and the measure(s) of fatness. Controls for demographic and socioeconomic characteristics are added in column (II) and controls for socioeconomic characteristics in childhood are included in column (III). Finally, controls for health are added in column (IV).

The results of Table 3 show that both BMI and waist circumference are negatively associated with the probability of being in employment for women. The elasticity of employment with respect to BMI in the specification that includes only age and BMI is -0.437 (Panel 1A, Column I). This compares to -0.558 for waist circumference (Panel 2A, Column I). The employment elasticity associated with waist circumference remains larger than the elasticity associated with BMI when additional covariates are included. In the regression that includes the full battery of covariates, the elasticity associated with waist circumference is -0.359 $(p<0.10)$, compared to -0.299 for BMI $(p<0.10)$.

Turning to the regressions in which categories of BMI and waist circumference are used, the results of Table 3 indicate that the probability of being employed for women with a BMI greater than or equal to 30 is 9.4 percentage points lower than for women with a BMI that does not exceed 30 (Panel 1C, Column I). Similarly, the probability of being employed is 10.4 percentage points lower for women in the top quintile of the waist circumference distribution compared to women in any of the other four quintiles 
(Panel 2C, Column I). The marginal effects decrease in size when the demographic and current socioeconomic characteristics are controlled for and decrease even further but remain statistically significant when controls for socioeconomic characteristics in childhood and health are included. The marginal effects in the specifications including the full battery of independent variables are roughly half of those estimated when the only controls included are age and the obesity measures.

\subsection{Correlation of fatness and obesity with employment for men}

Table 4 shows that, in contrast to the results for women, the elasticity of employment with respect to BMI is never significant at the $5 \%$ level for men (Panel 1A). However, the negative association between BMI and the probability of being in employment is statistically significant at the $5 \%$ level when BMI is dichotomised into obese (BMI $\geq 30$ ) and non-obese (BMI <30). Specifically, the probability of being employed is 5.3 percentage points lower for obese men when the only controls included are the obesity indicator and age (Panel 1C, Column I). The marginal effect decreases to 5.1 percentage points when the other demographic and socioeconomic characteristics are added to the model and decreases further to 4.6 percentage points when the socioeconomic characteristics in childhood are added. The negative association between obesity and employment probability is not statistically significant when the measures of health are included.

Turning to waist circumference, Table 4 shows that, similarly to the results for BMI, the elasticity of employment with respect to waist circumference is never significant at the 5\% level (Panel 1B). Another interesting result of Table 4, displayed in Panel $2 \mathrm{~B}$, is that the probability of being employed is highest for men falling into the middle quintile of the waist circumference distribution.

\subsection{Correlation of the other covariates with employment}

Tables 5 and 6 display the marginal effects associated with all the independent variables employed in the regressions of Tables 3 and 4 . Results are reported for

Table 6

Marginal effect [and $z$ statistics] associated with each independent variable from probit model (1: employed; 0 otherwise). Men only ( $N=1471$ ).

\begin{tabular}{|c|c|c|c|c|}
\hline & $(1)$ & $(2)$ & $(3)$ & $(4)$ \\
\hline \multicolumn{5}{|l|}{ Measures of fatness } \\
\hline BMI & $-0.001[0.39]$ & - & - & - \\
\hline Obese $(\mathrm{BMI} \geq 30)$ & - & $-0.019[0.85]$ & - & - \\
\hline Waist circumference & - & - & $-0.000[0.10]$ & - \\
\hline Waist circumference, quintile 5 & - & - & - & $-0.009[0.38]$ \\
\hline \multicolumn{5}{|l|}{ Demographic \& socioeconomic characteristics } \\
\hline Age & $-0.053^{* * *}[13.40]$ & $-0.053^{* * *}[13.34]$ & $-0.053^{* * *}[13.39]$ & $-0.053^{* * *}[13.37]$ \\
\hline Lives with spouse only & $-0.054[1.41]$ & $-0.054[1.41]$ & $-0.054[1.42]$ & $-0.054[1.42]$ \\
\hline Lives with spouse and/or others & $-0.007[0.19]$ & $-0.007[0.19]$ & $-0.007[0.19]$ & $-0.008[0.20]$ \\
\hline Lives in another town/city & $0.045[1.52]$ & $0.045[1.52]$ & $0.045[1.51]$ & $0.045[1.51]$ \\
\hline Lives in rural area & $0.046^{*}[1.73]$ & $0.047^{*}[1.74]$ & $0.046^{*}[1.72]$ & $0.046^{*}[1.72]$ \\
\hline Living children & $-0.005[0.80]$ & $-0.005[0.78]$ & $-0.005[0.83]$ & $-0.005[0.83]$ \\
\hline No/primary education & $-0.097^{* * *}[2.70]$ & $-0.096^{* * * *}[2.68]$ & $-0.096^{* * * *}[2.69]$ & $-0.096^{* * *}[2.66]$ \\
\hline Secondary education & $-0.066^{*}[2.45]$ & $-0.066^{* *}[2.45]$ & $-0.066^{* *}[2.46]$ & $-0.066^{* *}[2.46]$ \\
\hline Years spent in employment & $0.034^{* * *}[10.60]$ & $0.034^{* * *}[10.53]$ & $0.034^{* * * *}[10.60]$ & $0.034^{* * *}[10.53]$ \\
\hline \multicolumn{5}{|l|}{ Socioeconomic characteristics in childhood } \\
\hline Grew up in a poor family & $-0.050^{* * *}[1.97]$ & $-0.049^{*}[1.93]$ & $-0.050^{* *}[1.98]$ & $-0.050^{*}[1.95]$ \\
\hline Both parents working & $0.001[0.02]$ & $0.001[0.05]$ & $0.000[0.01]$ & $0.000[0.01]$ \\
\hline At least one parent secondary/tertiary education & $0.037[1.51]$ & $0.037[1.52]$ & $0.037[1.51]$ & $0.037[1.53]$ \\
\hline Missing information on parents' education & $-0.037[0.85]$ & $-0.038[0.86]$ & $-0.036[0.84]$ & $-0.037[0.84]$ \\
\hline \multicolumn{5}{|l|}{ Measures of physical health } \\
\hline Chronic diseases & $-0.020^{* *}[2.08]$ & $-0.019^{* *}[2.03]$ & $-0.020^{* *}[2.12]$ & $-0.020^{* * *}[2.10]$ \\
\hline Poor health & $-0.088^{* * *}[3.02]$ & $-0.087^{* * *}[2.99]$ & $-0.088^{* * * *}[3.03]$ & $-0.088^{* * *}[3.02]$ \\
\hline \multicolumn{5}{|l|}{ Measures of mental health } \\
\hline Depression score (CES-D) & $-0.003[1.40]$ & $-0.003[1.37]$ & $-0.003[1.40]$ & $-0.003[1.40]$ \\
\hline Life satisfaction & $-0.018^{*}[1.68]$ & $-0.019^{*}[1.71]$ & $-0.018^{*}[1.68]$ & $-0.018^{*}[1.68]$ \\
\hline \multicolumn{5}{|l|}{ Measures of behavioural health } \\
\hline Used to smoke & $-0.005[0.24]$ & $-0.006[0.25]$ & $-0.006[0.24]$ & $-0.005[0.24]$ \\
\hline Currently smokes & $-0.059^{*}[1.80]$ & $-0.060^{*}[1.84]$ & $-0.058^{*}[1.78]$ & $-0.058^{*}[1.81]$ \\
\hline Vigorous exercise & $0.071^{* * * *}[3.15]$ & $0.070^{* * * *}[3.13]$ & $0.072^{* * * *}[3.15]$ & $0.071^{* * * *}[3.16]$ \\
\hline Alcoholic drinks per day & $-0.006^{* * *}[2.06]$ & $-0.006^{* *}[2.00]$ & $-0.006^{* *}[2.07]$ & $-0.006^{* *}[2.07]$ \\
\hline Missing information on alcohol intake & $0.539^{* *}[2.00]$ & $0.526^{*}[1.94]$ & $0.541^{* *}[2.01]$ & $0.540^{* *}[2.01]$ \\
\hline
\end{tabular}

Note: Reference category for variables with at least three categories: lives alone; lives in Dublin; tertiary or higher education; both parents no/primary education; never smoked.

* Significant at $10 \%$ level.

** Significant at $5 \%$ level.

*** Significant at $1 \%$ level. $z$ statistics in parentheses. 
the models in which BMI and waist circumference are entered linearly and dichotomised. Table 5 lists the results for women, Table 6 for men.

Table 5 shows that for women, being older, living with a spouse and/or others, having no or primary education, being in poor health, reporting more chronic conditions and more depressive symptoms, being less satisfied and smoking at present are negatively associated with the probability of being in employment. Positive associations are found for the number of living children and the number of years spent in employment. The marginal effects associated with having a BMI exceeding 30 and being in the fifth quintile of the waist circumference distribution are -0.052 and -0.051 , respectively. Associations of similar magnitude are found for self-reported poor health and smoking at present. By comparison, the negative association between having no or primary education and the probability of being in employment is roughly three times larger.

Table 6 shows that for men, being older, having no, primary or secondary education, being in poor health, reporting more chronic conditions, being less satisfied and smoking at present are negatively associated with the probability of being in employment. In contrast to the results for women, having grown up in a poor family and drinking are also negatively associated with employment probability for men. Positive associations are found for vigorous exercise and the number of years spent in employment over the individual's lifetime. Focusing on categorical variables, the negative associations with employment are greatest for variables capturing whether the respondent has no or primary education and selfreports to be in poor health.

\section{Discussion and conclusions}

We examined the association between fatness and obesity and labour market status among older Irish adults using an anthropometric indicator of body composition (waist circumference) along with body mass index (BMI).

The results indicate that fatness and obesity are negatively associated with women's probability of being in employment. These results are largely consistent with those of Burkhauser and Cawley (2008) and Johansson et al. (2009). Burkhauser and Cawley (2008) investigate the associations between various measures of fatness and employment probabilities for American women aged 1865. They estimate separate models for white and African American women and include controls for age, education and marital status in the empirical model. The authors report that the employment elasticities associated with BMI and total body fat for white American women are -0.158 and -0.147 , respectively. In a similar model, we find that the elasticities associated with BMI and waist circumference are -0.433 and -0.550 , respectively.

Johansson et al. (2009) find a negative association between BMI, waist circumference and fat mass and employment probabilities among Finnish women. In the model controlling for age and education, they discover that having a high waist circumference is associated with approximately a 10 percentage point lower employment probability. We report a similar association: the probability of being employed is 8 percentage points lower for older Irish women in the fifth quintile of the waist circumference distribution compared to women in any of the other four quintiles.

In line with the results of Johansson et al. (2009), our results indicate a significant negative association between obesity and employment for women even after controls for health are included. This finding suggests that obesity might also influence women's employment probability through channels other than poor health. One possibility is that older obese women are discriminated against by employers, customers or co-workers based on their physical attributes. However, this is a hypothesis that cannot be tested with TILDA data.

The results for men indicate that employment is not significantly associated with BMI and waist circumference when these are entered linearly in the regression, but it is significantly and negatively associated with obesity defined either using BMI or waist circumference as categorical variables. In the model controlling for demographic and socioeconomic characteristics, the probability of being employed is 5.1 percentage points lower for men with a BMI equal to or greater than 30 and 4.6 percentage points lower for men in the fifth quintile of the waist circumference distribution. The results of Burkhauser and Cawley (2008) indicate that the probability of being employed is 3.0 percentage points lower for white American men with a BMI equal to or greater than 30 . However, this association is not statistically significant. Johansson et al. (2009) report that the probability of being employed is 10.8 percentage points lower for Finnish men with a high waist circumference.

Evidence that the use of categories, which capture possible nonlinearities, as opposed to continuous measures, influence the results for men is also found in the medical literature. For example, Angleman et al. (2006), who document the role of waist circumference and other measures of fatness in predicting disability in older American adults, find that the probability of reporting a difficulty with instrumental activities of daily living is lower for men in middle quartiles of the waist circumference and hip distributions compared to men in the bottom and top quartiles. Rhoads and Kagan (1983) use data from the Honolulu Heart Programme Study and find that mortality rates among men aged 4568 are highest in the lightest and heaviest quintiles. Similarly, Flegal et al. (2005) use data from the National Health and Nutrition Examination Survey and find that underweight and obesity are associated with increased mortality relative to the normal weight category.

In addition, the results of this paper indicate that among men there is no association between obesity and employment after controls for health are included. This finding suggests that factors other than health may be less important in explaining the association between obesity and labour market status for men. However, once again, this is only a hypothesis and cannot be tested with TILDA data.

Burkhauser and Cawley (2008, p. 519) argue that social science research on fatness and obesity would be enriched by greater consideration of more accurate measures of 
fatness and that, in the long run, social science datasets should include more measures of fatness. Candidates already employed in a limited number of studies are total body fat, percent body fat, fat mass, fat-free mass, waist circumference and waist-to-hip ratio.

The difficulty of obtaining measures such as body fat and fat-free mass is that the instruments required to measure them are not readily available or are prohibitively expensive, especially for survey purposes (Wada and Tekin, 2010). To date, the most inexpensive method is bioelectrical impedance analysis, in which "an electric current is sent through the subject's body, the degrees of resistance and reactance are measured, and afterwards converted into body fat and fat-free mass" (Bozoyan and Wolbring, 2011, p. 357). In contrast, measures including waist circumference and waist-to-hip ratio are less expensive and easier to collect, although for reasons of accuracy they need to be collected by trained interviewers or health professionals.

Earlier studies focusing on older adults have used only BMI to define fatness and obesity (Houston et al., 2009; Renna and Thakur, 2010; Lundborg et al., 2007). The results of this paper indicate that labour market outcomes of older adults might be sensitive to the measure of fatness employed. Using alternative but not necessarily more expensive measures of fatness in inferential or epidemiological studies is therefore an important avenue for future research.

The data and the methodology used in this paper have a number of strengths and limitations. Focusing first on the strengths, the data contain an extensive set of measures of health, current socioeconomic status and socioeconomic status in childhood. Measures of BMI and waist circumference were taken by qualified and trained nurses. Hence, neither measure suffers from individual reporting error. In addition, we focus on older workingage individuals, who have not been the focus of the literature up to the present.

Turning then to the limitations, we do not investigate the causal effect of obesity on employment. In the literature, there is a consensus that standard models might lead to biased results due to reverse causality and/or unobserved heterogeneity. The data used in this paper are cross-sectional, so fixed effects models that would account for unobservable heterogeneity at the individual level cannot be estimated.

In addition, a valid instrument that is correlated with and exogenous to individual obesity and uncorrelated with the error term in the employment equation was not available. Hence, only associations are reported in this study. We also investigate the association of obesity with only one labour market outcome: employment probability. The association of obesity with other labour market outcomes which have received attention in the literature, including wages, occupation and hours worked, is not investigated. Examining the association of obesity with these additional outcomes would have implied a significant drop in the number of observations on which the analysis is based. For example, information on number of hours spent at work was collected for 632 men. In comparison, the sample used in the analysis of this paper includes 1471 men.
In conclusion, we find that employment outcomes of Irish older working-age individuals are sensitive to fatness and obesity. From the perspective of the elderly individual, negative labour market outcomes including early labour market exit or reduced labour supply may result in a loss of income. Indirect effects can also be expected in terms of poorer mental and emotional health, which can in turn burden individual finances through additional medical expenditure (Harman et al., 2004; Lindeboom et al., 2002). From a broader perspective, obesity threatens to become an increasing burden for the entire tax-paying society, especially in the context of changing population demographics.

\section{Acknowledgements}

I would like to thank the Editor, four anonymous referees, Robert Wright, all the members of the TILDA team, and in particular Alan Barrett, Hilary Cronin, Eibhlin Hudson, Richard Layte, Claire O’Regan, Vincent O’Sullivan, George Savva and Doireann Wallace for insightful comments.

\section{References}

Abbott, R.D., Behrens, G.R., Sharp, D.S., Rodriguez, B.L., et al., 1994. Body mass index and thromboembolic stroke in non-smoking men in older middle age. The Honolulu heart program. Stroke 25, 2370-2376.

Angleman, S.B., Harris, T.B., Melzer, D., 2006. The role of waist circumference in predicting disability in periretirement age adults. International Journal of Obesity 30, 364-373.

Asgeirsdottir, T.L., 2011. Do body weight and gender shape the work force? The case of Iceland. Economics and Human Biology 9, 148156.

Atella, V., Pace, N., Vuri, D., 2008. Are employers discriminating with respect to weight? European evidence using quantile regression. Economics and Human Biology 6, 305-329.

Averett, S., Korenman, S., 1996. The economic reality of the beauty myth The Journal of Human Resources 31 (2) 304-330.

Baum II, C.L., Ford, W.F., 2004. The wage effects of obesity: a longitudinal study. Health Economics 13, 885-899.

Beaufrere, B., Morio, B., 2000. Fat and protein redistribution with aging: metabolic considerations. European Journal of Clinical Nutrition 54 (Suppl.) 48-53.

Becker, G., 1973. The Economics of Discrimination, second ed., vol. I. The University of Chicago Press, Chicago.

Bozoyan, C., Wolbring, T., 2011. Fat, muscles and wages. Economics and Human Biology 9 (4) 356-363.

Brunello, G., D'Hombres, B., 2007. Does body weight affect wages? Economics and Human Biology 5 (1) 1-19.

Burkhauser, R.V., Cawley, J., 2008. Beyond BMI: the value of more accurate measures of fatness and obesity in social science research. Journal of Health Economics 27, 519-529.

Burkhauser, R.V., Cawley, J., Schmeiser, M.D., 2009. The timing of the rise in US obesity varies with measure of fatness. Economics and Human Biology 7, 307-318.

Cawley, J., 2000. Body weight and women's labor-market outcomes. In: National Bureau of Economic Research Working Paper No. 7841.

Cawley, J., 2004. The impact of obesity on wages. Journal of Human Resources 39, 451-474.

Chyou, P.H., Burchfiel, C.M., Yano, K., Sharp, D.S., et al., 1997. Obesity, alcohol consumption, smoking, and mortality. Annals of Epidemiology 7 (4) 311-317.

Flegal, K.M., Graubard, B.I., Williamson, D.F., Gail, M.H., 2005. Excess deaths associated with underweight, overweight, and obesity. Journal of American Medical Association 293 (15) 1861-1867.

Garcia, J., Quintana-Domeque, C., 2007. Obesity employment and wages in Europe. In: Bolin, K., Cawley, J. (Eds.), Advances in Health and Health Services Research, The Economics of Obesity, vol. 17. Elsevier, New York.

Greve, J., 2008. Obesity and labour market outcomes in Denmark. Economics and Human Biology 6, 350-362. 
Hamermesh, D.S., Biddle, J.E., 1994. Beauty and the labor market. American Economic Review 84, 1174-1194.

Harman, J., Kelleher, H., Reynolds, C., Pincus, H., 2004. Out-of-pocket healthcare expenditures of older Americans with depression. Journal of American Geriatrics Society 52, 809-813.

Harrington, J., Perry, I., Lutomski, J., Morgan, K., et al., 2008. SLÁN 2007: Survey of Lifestyle, Attitudes and Nutrition in Ireland. Dietary Habits of the Irish Population, Department of Health and Children. The Stationery Office, Dublin.

Houston, D.K., Cai, J., Stevens, J., 2009. Overweight and obesity in young and middle age and early retirement: the ARIC study. Obesity 17 (1) 143-149.

Janssen, I., Katzmarzyk, P.T., Ross, R., 2004. Waist circumference and not body mass index explains obesity-related health risk. American Journal of Clinical Nutrition 79, 379-384.

Johansson, E., Böckerman, P., Kiiskinen, U., Heliövaara, M., 2009. Obesity and labour market success in Finland: the difference between having a high BMI and being fat. Economics and Human Biology 7 (1) 36-45.

Katz, D.A., McHorney, C.A., Atkinson, R.L., 2000. Impact of obesity on health-related quality of life in patients with chronic illness. Journal of General Internal Medicine 15, 789-796.

Komlos, J., Smith, P., Bogin, B., 2004. Obesity and the rate of time preference: is there a connection? Journal of Biosocial Science 36 (2) 209219.

Kragelund, C., Omland, T., 2005. A farewell to body-mass index? Lancet 366, 1589-1591

Lindeboom, M., Portrait, F., van den Berg, G.J., 2002. An econometric analysis of the mental-health effects of major events in the life of older individuals. Health Economics 11, 505-520.

Lindeboom, M., Lundborg, P., van der Klaauw, B., 2010. Assessing the impact of obesity on labor market outcomes. Economics and Human Biology 8, 309-319.

Lundborg, P., Bolin, K., Hojgard, S., Lindgren, B., 2007. Obesity and occupational attainment among the 50+ of Europe. Advances in Health Economics and Health Services Research 17, 219-251.

McGarry, K., 2004. Health and retirement: do changes in health affect the retirement expectations? Journal of Human Resources 39 (3) 624648.

Morris, S., 2006. Body mass index and occupational attainment. Journal of Health Economics 25, 347-364

Morris, S., 2007. The impact of obesity on employment. Labour Economics $14,413-433$

Norton, E., Han, E., 2008. Genetic information, obesity and labor market outcomes. Health Economics 17, 1089-1104.

O'Regan, C., Cronin, H., Kenny, R.A., 2011. Mental health and cognitive function. In: Barrett, A., Savva, G., Timonen, V., Kenny, R.A. (Eds.), Fifty Plus in Ireland 2011: First Results from the Irish Longitudinal Study on Ageing. Trinity College Dublin, pp. 155-202.

Offner, A., 2001. Body weight and self-control in the United States and Britain since the 1950s. Social History of Medicine 14 (1) 79-106.

Pagan, J.A., Davila, A., 1997. Obesity, occupational attainment, and earnings. Social Science Quarterly 78, 756-770.

Pi-Sunyer, F.X., 2002. The obesity epidemic: pathophysiology and consequences of obesity. Obesity Research 10, 97-104.

Pouliot, M.C., Despres, J.P., Lemieux, S., Moorjani, S., et al., 1994. Waist circumference and abdominal sagittal diameter: best simple anthropometric indexes of abdominal visceral adipose tissue accumulation and related cardiovascular risk in men and women. The American Journal of Cardiology 73, 460-468.

Prescott, E., Scharling, H., Osler, M., Schnohr, P., 2002. Importance of light smoking and inhalation habits on risk of myocardial infarction and all cause mortality. A 22-year follow-up of 12,149 men and women in the Copenhagen City Heart Study. Journal of Epidemiology and Community Health 56, 702-706.

Register, C.A., Williams, D.R., 1990. Wage effects of obesity among young workers. Social Science Quarterly 71, 130-141.

Renna, F., Thakur, N., 2010. Direct and indirect effects of obesity on US labor market outcomes of older working age adults. Social Science \& Medicine 71 (2) 405-413.
Rhoads, G.C., Kagan, A., 1983. The relation of coronary disease, stroke, and mortality to weight in youth and in middle age. Lancet 1, 492-495.

Roberts, R.E., Deleger, S., Strawbridge, W.J., Kaplan, G.A., 2003. Prospective association between obesity and depression: evidence from the Alameda County Study. International Journal of Obesity and Related Metabolic Disorders 27, 514-521.

Rooth, D., 2009. Obesity, attractiveness and differential treatment in hiring - a field experiment. Journal of Human Resources 44 (3) 710-735.

Sabia, J.J., Rees, D.I., 2012. Body weight and wages: evidence from Add health. Economics and Human Biology 10, 14-19.

Sarlio-Lahteenkorva, S., Lahelma, E., 1999. The association of body mass index with social and economic disadvantage in women and men. International Journal of Epidemiology 28, 445-449.

Savva, G., 2011. Methodology. In: Barrett, A., Savva, G., Timonen, V., Kenny, R.A. (Eds.), Fifty Plus in Ireland 2011: First Results from the Irish Longitudinal Study on Ageing. Trinity College Dublin, pp. 293303.

Shimokawa, S., 2008. The labour market impact of body weight in China: a semiparametric analysis. Applied Economics 40, 949-968.

Simon, G.E., Ludman, E., Linde, J., Operskalski, B.G., et al., 2008. Association between obesity and depression in middle-aged women. General Hospital Psychiatry 30, 32-39.

Snijder, M.G., Visser, M., Dekker, J.M., et al., 2002. The prediction of visceral fat by dual-energy X-ray absorptiometry in the elderly: a comparison with computed tomography and anthropometry. International Journal of Obesity and Related Metabolic Disorders 26, 984993.

Stewart, K.J., DeRegis, J.R., Turner, K.L., Bacher, A.C., et al., 2003. Usefulness of anthropometrics and dual-energy X-ray absorptiometry for estimating abdominal obesity measured by magnetic resonance imaging in older men and women. Journal of Cardiopulmonary Rehabilitation and Prevention 23, 109-114.

Tucker-Seeley, R.D., Subramanian, S.V., 2011. Childhood circumstances and height among older adults in the United States. Economics and Human Biology 9, 194-202.

van Dijk, S.B., Takken, T., Prinsen, E.C., Wittink, H., 2012. Different anthropometric adiposity measures and their association with cardiovascular disease risk factors: a meta-analysis. Netherland Heart Journal 20 (5) 208-218.

Villar, J.G., Quintana-Domeque, C., 2009. Income and body mass index in Europe. Economics and Human Biology 7, 73-83.

Villareal, D.T., Apovian, C.M., Kushner, R.F., Klein, S., 2005. Obesity in older adults: technical review and position statement of the American Society for Nutrition and NAASO. The Obesity Society. American Journal of Clinical Nutrition 82 (5) 923-934.

Wada, R., Tekin, E., 2010. Body composition and wages. Economics and Human Biology 8, 242-254.

Wan, Y., Colditz, G., Kuntz, K., 2007. Forecasting the obesity epidemic in the aging US population. Obesity 15 (11) 2855-2865.

Wen, C.P., Wai, J.P.M., Tsai, M.K., Yang, Y.C., et al., 2011. Minimum amount of physical activity for reduced mortality and extended life expectancy: a prospective cohort study. Lancet 378, 1244-1253.

Whelan, B.J., 1979. RANSAM: a random sample design for Ireland. Economic and Social Review 10, 169-174.

WHO [World Health Organization], 1995. Physical Status: the Use and Interpretation of Anthropometry. Report of a WHO Expert Committee, Geneva.

WHO [World Health Organization], 2003. Diet, Nutrition and the Prevention of Chronic Diseases. Report of a Joint WHO/FAO Expert Consultation, Geneva.

WHO [World Health Organization], 2012a. Obesity and Overweight. Fact sheet No. 311. Available in the Internet at:http://www.who.int/ mediacentre/factsheets/fs311/en/.

WHO [World Health Organization], 2012b. The WHO Global InfoBase. Available in the Internet at:https://apps.who.int/infobase/.

Zamboni, M., Turcato, E., Armellini, F., Kahn, H.S., et al., 1998. Sagittal abdominal diameter as a practical predictor of visceral fat. International Journal of Obesity and Related Metabolic Disorders 22, 655-660. 